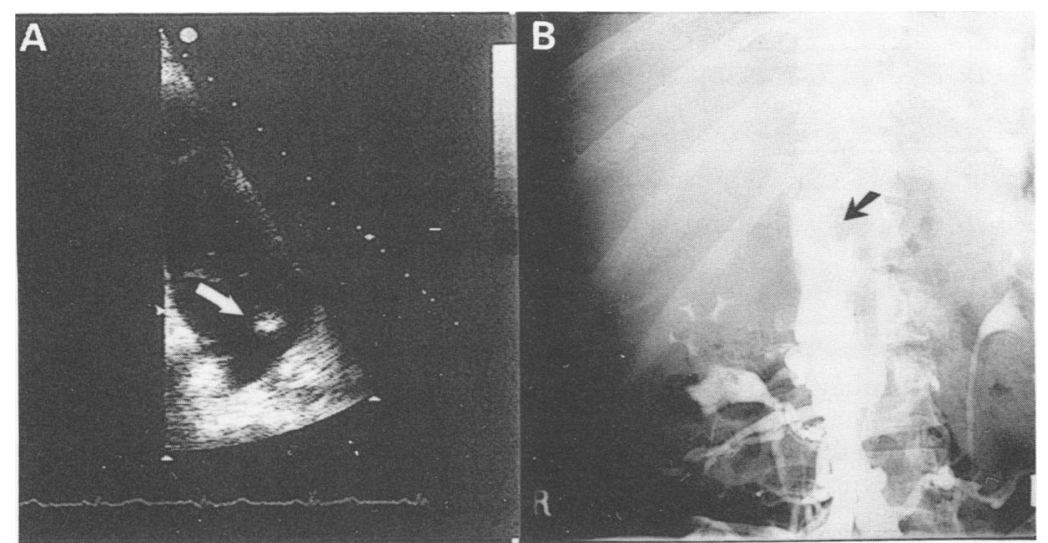

A: Pre-treatment $2 D$ echocardiogram showing right atrial thrombus (arrow); B: IVC angiogram demonstrating the level of obstruction (arrow).

(sterile skin pustules at sites of venepuncture) was noticed. There was evidence of penile and scrotal scarring. Prominent distended veins over the anterior abdominal wall and lower chest were present.

His chest radiograph was normal and repeat $2 \mathrm{D}$-echocardiogram showed a sessile $1 \mathrm{~cm}$ diameter mass within the right atrium, lying above the inflow of the inferior vena cava (IVC) and attached to the posterior wall (fig A). A venogram revealed occlusion of the IVC with extensive collateral circulation (fig B) and abdominal CT showed patchy inhomogeneity of the liver with enlargement of the caudate lobe and virtually no visualisation of the hepatic veins.

An elevated serum factor VIII RAg (510 IU/dl) and weakly positive neutrophil cytoplasmic (perinuclear pattern) antibodies were observed.

Behçet's disease was diagnosed, complicated by Budd-Chiari syndrome and right atrial thrombus.

He was treated with warfarin, prednisolone (40 $\mathrm{mg} /$ day, reduced over 12 months to $15 \mathrm{mg} /$ day) and azathioprine (125 mg/day). On review after three months of treatment there was no hepatomegaly and we did not observe any distended abdominal veins. 2D-echocardiography showed reduction in the size of the right atrial mass. The level of factor VIII RAg diminished (320 IU/dl) and neutrophil cytoplasmic antibodies were not detectable.

At six months follow up, bilateral cataracts and mild retinal vasculitis developed. The first improved after reducing his steroids and the latter has not advanced when reviewed 18 months later. Transoesophageal echocardiography at this stage showed no evidence of the thrombus in the right atrium.

Mass in the right atrium may be due to a primary or metastatic tumour, endocarditis involving the right side of the heart, or thrombus formation $4-6$

Thrombus within the right ventricle was first described at necropsy in a patient with Behçet's disease who presented with haemoptysis and pulmonary lesions. ${ }^{7}$ In two other reports it was observed either at necropsy or after surgery. ${ }^{38}$ In our case this rare complication of Behçet's disease was diagnosed by 2D-echocardiography and successfully treated with a combination of anticoagulation and immunosuppressive therapy.

1 his report confirms that right atrial thrombus occurs in association with Behcet's syndrome and can be successfully treated by medical means.
We thank Dr C Clarke, Russels Hall Hospital, Dudley, Dr B Cooper, Dudley Road Hospital, Mr P Murray, The Birmingham Eye Hospital and Dr J DeGiovanni, The Birmingham Childrens Hospital for their help in the management of this patient.

ISMAIL F ISLIM

MARTIN D GIL DEVA SITUNAYAKE ROBERT D S WATSON Cardiology and Rheumatology Departments Dudley Road Hospital United Kingdom

Correspondence to: Dr Ismail F Islim, Cardiology Department, Dudley Road Hospital, Birmingham Department, Dudley Road

1 Behçet's $H$. Uber rezidivierende Aphthose durch ein virus versuchate Geshwure am Mund. Am Auge und an den Gentalien. Derm Wschr 1937; 105: 1152.

2 Kansu E, Ozer F L, Akalin E, et al. Behçet's syndrome with obstruction of the venae cavae. A report of seven cases. Ouarterly $\mathscr{f}$ Med 1972; 41: 131-68.

3 McDonald G S A, Gad Al-Rab. Behçet's disease with endocarditis and the BuddChiari syndrome. $f$ Clin Path 1980; 33: 660-9.

4 Kapoor A S. Clinical manifestations of neoplasia of the heart. In: Kapoor A S, ed. Cancer and the heart. New York: SpringerVerlag, 1986; 21-5.

5 Schoen F J, Berger B M, Guerina N G. Cardiac effects of non-cardiac neoplasia. Cardiol Clin 1984; 2: 657

6 Rajpal R S, Leibsohn S A, Lickweg W G, et al. Infected left atrial myxoma with bacteraemia simulating infective endocarditis. Arch Inter Med 1979; 139: 1176 .

7 Davies J D. Behçet's disease with haemoptysis and pulmonary lesions. $f$ Pathol 1973; 109, 351-6.

8 Candan I, Erol C, Sonel A, et al. Behçet's disease, cardiac and pulmonary involvement. Europ $H \mathcal{f}$ 1986; 7: 999-1002.

\section{Dyslipoproteinaemia in a subset of patients with rheumatoid arthritis}

It has been clearly established that patients with rheumatoid arthritis (RA) have an accelerated mortality in comparison with the general population. ${ }^{1-3}$ The primary cause of death for patients with RA is cardiovascula disease. Although one older study suggested otherwise, ${ }^{4}$ several more recent series have concluded that the incidence of atherosclerotic cardiovascular disease (ASCVD) in patients with RA may exceed that of controls. ${ }^{2}{ }^{3}$ Risk factors for the development of ASCVD include male sex, family history, cigarette smoking, hypertension, diabetes mellitus, and dyslipoproteinaemia. ${ }^{5}$ Lipoprotein profiles that predispose to the development of ASCVD include high levels of total cholesterol (TC) or low density lipoprotein cholesterol (LDL-C), and low levels of high density lipoprotein cholesterol (HDL-C). In several series, patients with RA have been shown to have serum cholesterol concentrations significantly lower than controls. ${ }^{67}$ However, such studies have usually included a significant proportion of persons with few risk factors for ASCVD, for example young women. We have investigated the serum lipoprotein profile of a group of older males with RA.

Sixty male patients with RA followed at the Dallas Department of Veterans Affairs Medical Center arthritis clinic were evaluated. Patients who were receiving treatment with lipid-lowering agents, as well as patients with diabetes mellitus or thyroid disease, were excluded from analysis. The average mean (SD) age of the patients was 62 (11) years. All patients were receiving treatment with disease modifying antirheumatic drugs (methotrexate 23, sulfasalazine 13, injectable gold 12 , D-penicillamine 9 , auranofin 1 azathioprine 1 , cyclophosphamide 1). Thirty three patients $(55 \%)$ were receiving therapy with corticosteroids [mean (SD) dose for those receiving prednisone: $6.8(3.4) \mathrm{mg} /$ day; median dose $5 \mathrm{mg} /$ day (range 4-20)]. Twenty two patients were being treated with antihypertensives, including four patients treated with a $\beta$-blocker and five with a diuretic Fasting cholesterol, HDL-C, and triglycerides (TG) were determined enzymatically. LDL-C was estimated using the formula LDL-C= TC - (HDL-C + TG/5)

Lipoprotein profiles are shown in the table. Although mean values are within normal range, a substantial number of patients have concentrations of lipoproteins considered to be a risk for the development of ASCVD. Thus 11/60 (18\%) patients would be considered at 'high risk' of developing ASCVD on the basis of TC or LDL-C, according to National Cholesterol Education Programs recommendations $(\mathrm{TC} \geqslant 6.21 \mathrm{mmol} / \mathrm{L}$ [240 $\mathrm{mg} / \mathrm{dL}] ; \quad \mathrm{LDL}-\mathrm{C} \geqslant 4 \cdot 14 \mathrm{mmol} / \mathrm{L}$ [160 mg/dL]). ${ }^{5}$ Furthermore, it has been established that persons within this particular population (that is, male veterans) often possess multiple additional risk factors for ASCVD. ${ }^{8}$ Therefore, $8 / 60$ (13\%) additional patients with 'borderline risk' levels of TC and $\mathrm{LDL}-\mathrm{C} \quad(\mathrm{TC} \geqslant 5.17 \mathrm{mmol} / \mathrm{L} \quad[200 \mathrm{mg} / \mathrm{dL}]$ $\mathrm{LDL}-\mathrm{C} \geqslant 3.36 \mathrm{mmol} / \mathrm{L}$ [130 $\mathrm{mg} / \mathrm{dL}]$ ) would be considered to have significant dyslipoproteinaemia. Recently, the important role of decreased levels of HDL-C as a risk factor for ASCVD has been increasingly appreciated. ${ }^{9}$ Of note, $30 / 60(50 \%)$ of the patients had depressed serum HDL-C $(\leqslant 0.91 \mathrm{mmol} / \mathrm{L}$ [35 mg/dL]), of whom $12 / 60(20 \%)$ had concentrations $\leqslant 0.78 \mathrm{mmol} / \mathrm{L}(30 \mathrm{mg} / \mathrm{dL})$. In total, $41 / 60$ patients $(68 \%)$ had serum concentrations of TC, LDL-C, or HDL-C that would be considered risk factors for the development of ASCVD. In contrast to other studies, ${ }^{9}$ there was no correlation between the use of corticosteroids and serum concentrations of TC, TG, HDL-C, or LDL-C. A similar lack of correlation has been noted in some studies, ${ }^{7}$ and may relate to the intrinsic propensity toward dyslipoproteinaemia in the specific populations analysed.

It is accepted that the mortality of patients with RA is accelerated and that ASCVD is an important contributory factor. It has been 
Serum lipoproteins in 60 male patients with $R A$

\begin{tabular}{|c|c|c|c|c|}
\hline $\begin{array}{l}\text { Mean }(S D)(m m o l / L) \\
{[m g / d L]}\end{array}$ & $\begin{array}{l}T C \\
+\cdot 91(1 \cdot 22) \\
{[189(+7)]}\end{array}$ & $\begin{array}{l}T G \\
17.1(0.90) \\
{[151(80)]}\end{array}$ & $\begin{array}{l}H D L-C \\
0 \cdot 96(0 \cdot 31) \\
{[37(12)]}\end{array}$ & $\begin{array}{l}L D L-C \\
3 \cdot 15(1 \cdot 01) \\
{[121(39)]}\end{array}$ \\
\hline $\begin{array}{l}\text { Number of patients with } \\
\text { indicated values ( }(1 / 1)\end{array}$ & $\begin{array}{l}25.17 \mathrm{mmol} / \mathrm{L} \\
{[200 \mathrm{mg} / \mathrm{dL}]} \\
19 / 60(32 \%) \\
26.21 \mathrm{mmol} / \mathrm{L} \\
{[240 \mathrm{mg} / \mathrm{dL} .]} \\
9 / 60(15 \%)\end{array}$ & & $\begin{array}{l}00.91 \mathrm{mmol} / \mathrm{L} \\
{[35 \mathrm{mg} / \mathrm{dI} .]} \\
30 / 60(50 \%) \\
00 \cdot 78 \mathrm{mmol} / \mathrm{L} \\
{[30 \mathrm{mg} / \mathrm{dL}]} \\
12 / 60(20 \%)\end{array}$ & $\begin{array}{l}\geqslant 3.36 \mathrm{mmol} / \mathrm{L} \\
{[130 \mathrm{mg} / \mathrm{dL}]} \\
19 / 60(32 \%) \\
\geqslant 4.14 \mathrm{mmol} / \mathrm{L} \\
{[160 \mathrm{mg} / \mathrm{dL}]} \\
10 / 60(17 \%)\end{array}$ \\
\hline
\end{tabular}

suggested that patients with RA have depressed cholesterol concentrations. However, this study indicates that subpopulations of RA patients may have dyslipoproteinaemia, including hypercholesterolaemia, that would place them at an enhanced risk of developing ASCVD. The prevalence of dyslipoproteinaemia in this population may approximate or exceed that of the general age and sex matched population. In the most recent US national health and nutrition examination survey (NHANES III), approximately $60 \%$ of males over 55 years of age had high risk or borderline-high risk lipid profiles." However, the definitive comparison group would require matching cases and controls not only in terms of age and sex, but also regarding the presence of secondary factors predisposing to dyslipoproteinaemia, including obesity, dietary habits (for example, intake of saturated fats and ethanol), and endocrinopathies.
Limitations of this study include the single measurement of lipoproteins, which may be unstable over time, and the estimation rather than direct measurement of LDL-C. Nevertheless, such screening measurements may realistically approximate evaluation techniques that tend to be utilised in clinical practice. The finding of dyslipoproteinaemia in a majority of this subset of patients with RA would be of significance in attempts to mollify the enhanced risk of ASCVD related mortality in such patients. Further, this is particularly germane if such patients may possess additional risk factors for ASCVD, as might be expected in this particular population of older male veterans.

ARTHUR KAVANAUGH

Dallas Department of Veterans Affairs Medical Center
The University of Texas

Dallas 1) partme'nt of Veterans Affairs Medical Center
The University of Texas Southaestern Medical Center 5323 Harm Hines Bonlezard
allas, Texas $75235-8577$, USA
1 Pincus $\mathrm{T}$, Callahan L F. Taking mortality in rheumatoid arthritis seriously-predictive markers, socioeconomic status and $\mathrm{CO}^{-}$ morbidity $841-5$

2 Isomäki H A, Mutru O, Koota K. Death rate and causes of death in patients with rheumatoid arthritis. Scand $\mathcal{f}$ Rheumatol $1975 ; 4: 205-8$.

3 Prior P, Symmons D P M, Scott D L, rheumatoid arthritis. $\mathrm{Br}$ f Rheumatol 1984; 23: 92-9.

4 Bonfiglio T, Atwater E C. Heart disease in patients with seropositive rheumatoid patients with seropositive rheumatoid

5 The Expert Panel on Population Strategies for Blood Cholesterol Reduction. National Cholesterol Education Program. Arch Inter Med 1991; 151: 1071-84

6 Lazarevic M B, Vitic J, Mladenovic V Myones B I, Skosey J I, Swedler W I Dyslipoproteinemia in the course of active rheumatoid arthritis. Seminar Arthritis Rheum 1992; 22: 172-80.

† Rantapää-Dahlqvist S, W'ällberg-Jonsson S Dahlen (G. Lipoprotein (a), lipids, and lipoproteins in patients with rheumatoid arthritis. proteins in patients with rheumatoic

8 Richlie D G, Winters S, Prochazka A V. Dyslipidemia in veterans: multiple risk factor may break the bank. Arch Intern Med 1991 151: $1433-6$

9 Rosenson R S. Low levels of high-density lipoprotein cholesterol (hypoalphalipoproteinemia). Arch Intern Med 1993; 153: 1528-38.

10 Blum R L. Computer-assisted design of studies using routine clinical data: analyzing the association of prednisone and cholesterol Ann Intern Med 1986; 104: 858-68.

11 Sempos C T, Cleeman I I, Carroll M D), et al. Prevalence of high blood cholesterol among US adults. FAMA 1993;269: 3009-14. 